


\section{Objetivo e Hipótese}

Com o presente estudo, objetiva-se investigar a representação simbólica do câncer em profissionais da área de saúde, pacientes, familiares e população em geral. Tem como hipótese o fato de a imagem simbólica negativa do câncer contribuir para a insuficiência de iniciativa da população em cuidados preventivos.

De fato, tal alheamento gera um tempo prolongado e perigoso entre os primeiros sinais e a consulta médica. Em decorrência, o prognóstico pode tornar-se ruim para o paciente, seus familiares e a sociedade. Embora muitos tipos de câncer tenham cura, devido ao fato de a procura dos recursos médicos ser tardia, o paciente pode iniciar seu tratamento em estádio avançado, limitando-se as possibilidades de tratamento.

Após o consentimento de um paciente para este estudo, foi-lhe aplicado um questionário com perguntas dirigidas e específicas (Anexo1) para a investigação da imagética do câncer constituída em seu macro e microssistema.

O critério primeiro para que o pesquisado fosse objeto deste estudo foi que tivesse condições cognitivas preservadas e autonomia nas respostas. Também não podia estar sob o efeito de medicamentos que tivessem interferência no sistema nervoso central.

Por sua vez, os médicos ou profissionais de enfermagem da clínica oncológica ou hematológica deviam ter, pelo menos, três anos de atuação na clínica específica ou ter acompanhado o tratamento de pelo menos cem pacientes com neoplasias.

Os psicólogos apresentam, no mínimo, cinco anos de experiência na clínica hospitalar e todos os entrevistados têm idade superior a dezoito anos.

Com este estudo, reafirma-se a necessidade de um trabalho social de conscientização da experiência e dos recursos de tratamentos atuais, para que o conhecimento científico suplante a negatividade histórica da influência simbólica do câncer. Além disso, novas terapêuticas deverão ser estudadas e estabelecidas, para que a representação simbólica passe por um trabalho reflexivo, pois isso pode ser a base de uma possível transformação, cuja mudança deverá repercutir na satisfação da demanda de cuidados preventivos.

\section{Introdução}

De acordo com Simonton et al (1978, p. 80), é indiscutível o prejuízo causado pelas expectativas negativas, pois as crenças preconcebidas existentes na sociedade e no campo médico, em relação ao câncer, causam malefícios diretos ao paciente.

Verifica-se, na população em geral, a presença da proliferação marcante das seguintes idéias: “a) $o$ câncer é sinônimo de morte; b) o câncer é algo que ataca do exterior e não há como controlá-lo; c) o tratamento - quer seja por radioterapia, quimioterapia ou cirurgia - é drástico e negativo e, quase sempre, tem efeitos colaterais desagradáveis".

O efeito mais devastaDOR é que as expectativas são demarcadas pela imagem da própria dor e da morte, gerando uma espécie de "profecia autoelaborada". Em vez de conseguir aceitar o processo e realizar o enfrentamento, sucede-se a maximização das dificuldades.

A qualidade negativa que encobre a constituição do câncer funciona como uma venda que bloqueia a percepção e a manifestação eficiente dos mecanismos de defesa mental e imunológica, afirma Leshan (1992). Conforme o autor, é comum a expressão rudimentar do mecanismo de negação, análoga à crosta que se forma sobre a ferida, como proteção, até o processamento da cura. Nesse momento, a crosta perde a razão de permanecer e cai.

"Saber não basta.

Arrisque unir o

conhecimento à ação

e então saberá se é

genuíno, se é

pretensão ou apenas

informação".

Karpinski (1990, p. 145)

De fato, ao se fazer a comunicação diagnóstica, verifica-se o aparecimento dessa "crosta" como proteção contra o impacto e a sobrecarga seqüencial que o imaginário aponta. No entanto, a imagem elaborada pode desenvolver um efeito negativo na conduta do paciente, e este mantém a "crosta protetora" por um período além do devido. Por conseqüência, deixa de ser benéfica. $\bigcirc$ que era defesa torna-se fraqueza, e, pela dificuldade de acesso à própria fonte de forças, observa-se a demarcação exacerbada das perdas e a inexistência dos recursos pessoais para o enfrentamento necessário.

É fundamental criar-se oportunidade de expressão das emoções que se processam no decorrer do adoecimento. Mas, como manter um fluxo adequado e valoroso da comunicação, se a imagem internalizada indica a percepção da impotência profissional perante o descontrole celular? A ocorrência das curas no campo do real não garante o crédito no campo simbólico.

Para Guerriero et al (2001, p. 100) "o que estabelece a noção de verdade é a crença envolvida nas representações simbólicas. A lógica do imaginário é passível de ser construída e reconstruída e é distinta da simples ilusão. O imaginário tem relações com a vida circundante, é constituído e legitimado socialmente". 
Worden (1998) propõe algumas técnicas, como a intervenção no processo de luto. Entre elas, menciona a reestruturação cognitiva como forma de estimular a manifestação de pensamentos e sentimentos provenientes da perda real ou imaginária. Fica subentendida, nessa proposta, a interferência dos pensamentos sobre os sentimentos, inclusive os pensamentos encobertos e os que estão diretamente relacionados ao próprio sujeito na forma como ele se sustenta em sua subjetividade.

Segundo Leshan (1992, p. 28), no período que antecede a instalação do câncer, ou seja, antes dos primeiros sinais da proliferação caótica celular, existe um padrão de perda da esperança em $70 \%$ a $80 \%$ das pessoas que adoecem, enquanto apenas $10 \%$ apresenta esse comportamento no grupo em que inexistia o câncer. Para ilustrar o achado, ele cita o poeta W. H. Auden, que define o câncer como "um fogo criativo derrotado".

A prática diária também registra a existência de atitudes individuais de autocura. Nesse contexto, o problema está no fato de não se saber, com consistência científica, como acionar e manter o processo de resgate da saúde. Porém, sabe-se que, nas situações em que o processo de autocura se estabelece, ocorre um aumento de respostas qualitativas.

Desde 1811, os dicionários incluem o significado da palavra placebo, ou seja, de uma substância que não tem nenhum efeito biológico. Verificouse que, quando havia um relacionamento de confiança entre o médico e o paciente, a utilização do placebo apresentava respostas favoráveis e amenizava a condição clínica. Assim, a crença da positividade da intervenção médica dá viabilidade ao sistema de auto-renovação do paciente, que pode não ser suficiente, mas que torna mais eficiente a própria defesa e a busca do bem-estar (Leshan, 1992).

Até 1900, os médicos, xamãs e curandeiros faziam uma relação direta entre o câncer e os fatores psicológicos. Aceitavam a hipótese de que havia uma correlação entre a história da vida emocional e a evolução da doença.

Tais interpretações foram, gradativamente, sendo elaboradas pela rotina de consultas, em que a escuta era um instrumento diagnóstico, pois não existiam testes bioquímicos, nem raio $x$, nem tomografia axial computadorizada. Em conseqüência, as perguntas abrangiam o campo da história de vida dos pacientes e estes, por sua vez, revelavam o filme dos seus sentimentos de desesperança e as perdas vivenciadas antes do aparecimento da doença.
Com a evolução da tecnologia e da ciência, descobriram-se novas intervenções: cirurgia, quimioterapia, radioterapia, transplantes; então, o olhar tornou-se focal, isto é, restringiu-se à parte específica do corpo adoecido e não mais ao funcionamento do ser humano como um todo. Assim, em linhas gerais, o câncer passou a ser visto como um problema corporal localizado.

Após 1950, a forma de análise interpretativa em relação ao câncer sofreu outra mudança. Novamente, a história de vida emocional e cognitiva passou a ser considerada e incluída nos fatores que poderiam exercer interferência no aparecimento, na manutenção e na evolução do câncer.

Apesar dos avanços científicos e da revolução tecnológica, o conceito do câncer mantém explicações arcaicas e, por vezes, irrealistas. Os recursos terapêuticos ampliaram-se significativamente, mas o problema e as questões são os mesmos, ou seja: como sanar a vulnerabilidade detonada pela imagética?

Na medida em que o fantasma da morte acompanha o paciente em seus movimentos, espera-se que esta investigação traga algum conhecimento que nos auxilie a elaborar terapêuticas mais satisfatórias e precisas.

\section{Câncer: o Olhar de Cada um}

Iniciou-se este trabalho por meio de um estudo piloto, com vinte e dois profissionais de enfermagem da hematologia e oncologia. O questionário (Anexo 1) foi composto de oito perguntas, com o objetivo de se obter respostas subjetivas para verificar a representação simbólica do câncer.

Os resultados indicaram informações ricas de subjetividade, independentemente das diferenças nos caracteres demográficos. Além disso, as respostas apresentaram alguns elementos primitivos, com explicações análogas à natureza, como: "o câncer é como um formigueiro, as formigas trabalham quietinhas, mas, se chutarem o formigueiro ninguém segura!". "É um dragão que te devora". "É como uma erva daninha que rasteia, aí não tem jeito não!" (Sic).

Tais associações são encontradas na etimologia da palavra câncer, em sua historicidade e primordiais impressões. Supostamente, com o avanço da tecnologia e da ciência, do número de sobreviventes, da busca pela qualidade de vida, esperavam-se respostas com menos teor mórbido. Porém, tal impressão se mantém, apesar de a realidade apresentar conquistas significativas. 
Também foi possível observar que, após o décimo entrevistado, as respostas posteriores não apresentaram variações qualitativas significativas. Vale destacar que a pesquisa foi feita em dez entrevistas para cada grupo, conforme a amostra a seguir:

Tabela - Universo entrevistado

\begin{tabular}{c|c} 
Grupo Número Gênero Hospital & Fora do \\
F $M$ & Hospital
\end{tabular}

\begin{tabular}{|l|l|l|l|l|l|}
\hline Médico & 10 & 4 & 6 & $\mathrm{X}$ & \\
\hline Enfermagem & 10 & 8 & 2 & $\mathrm{X}$ & \\
\hline Psicólogo & 10 & 7 & 3 & $\mathrm{X}$ & \\
\hline Paciente & 10 & 6 & 4 & $\mathrm{X}$ & \\
\hline $\begin{array}{l}\text { Familiar } \\
\text { Externo ao }\end{array}$ & 10 & 6 & 4 & $\mathrm{X}$ & \\
$\begin{array}{l}\text { hospital } \\
\text { Total }\end{array}$ & 10 & 6 & 4 & & $\mathrm{X}$ \\
\hline
\end{tabular}

As respostas foram categorizadas conforme a temática da percepção apresentada pelas pessoas entrevistadas. A classificação compõe os seguintes tópicos: a) morte; b) aprendizagem e mudança de valores; c) perdas secundárias ao tratamento; d) razões emocionais; e) crença/estigma; f) explicação teórica. A seguir, elas serão apresentadas para que sejam transmitidos os respectivos fenômenos interferentes na imagética do câncer.

\section{Grupo de Médicos \\ (Para Você: o Que Significa "Câncer"?)}

A temática das respostas está concentrada no item da explicação teórica, mas, quando há ausência da referência científica nos relatos, descobre-se uma miscelânea de justificativas, que vão desde crenças descabidas até a impotência diante da morte. Apenas 1/10 dos médicos apresentou a necessidade de mudar os planos e projetos de vida devido à consciência da finitude e ao desejo de uma saúde global. Eis algumas das respostas obtidas:

"É uma moléstia, é uma doença horrorosa. É cheia de tabus e só de pensar que você tem câncer, já acontece uma associação com a morte"; "É uma auto-destruição, é uma alteração do seu psicológico que altera o sistema imunológico e este dá chance para isto acontecer"; "É um tiro no escuro".

O que fica escondido na própria fala que diz ser melhor não adentrar na temática do câncer?

Segundo Nunes Silva (2000, p. 148), "o grande temor dos médicos é de que os pacientes se deprimam, desistam do tratamento e, por conseguinte, renunciem prematuramente à luta pela própria vida". Na desistência da vida, resta ao médico cuidar da morte, embora sua formação acadêmica o tenha preparado para a cura, e não para a morte. Além disso, ninguém possui informações sobre o dia e a hora da própria morte. Ainda assim, pacientes portadores de mau prognóstico podem surpreender, vivendo além das expectativas, e pacientes com probabilidades estatísticas favoráveis podem apresentar complicações inesperadas e falecer. Nessa contradição, o clínico mantém a tradição de vislumbrar o desejo da cura mesmo que, ao ser associado à morte, o câncer passe a ser maldição não desejada para o convívio.

Exige-se do médico que seja tecnicamente competente e humanamente acolhedor. Contudo, é preciso considerar que a grade curricular das escolas de Medicina do Brasil não oferece conhecimentos suficientes para uma eficaz compreensão das implicações biopsíquicas do doente.

Nessa perspectiva, Nunes Silva (2000) aponta a necessidade premente de incluir no curriculum médico conteúdos de Psicologia, Antropologia e Sociologia, de modo que se estabeleça uma relação mais salutar entre o pensar, o agir e o sentir.

Dessa forma, poder-se-ia propiciar uma incorporação clínica para além da doença, ou seja, o doente estaria incluído no contexto de uma possibilidade a mais de expressão e acolhimento, não se mantendo recluso na solidão que o abate.

No entanto, como inserir o doente, contemplálo com atendimento de modo mais amplo, se a imagem primordial é de que se trata apenas de uma questão de tempo para o enfermo estar incluído na lista dos óbitos?

Nunes Silva (2000, p. 240) afirma que: "deve-se procurar desmitificar crenças aterradoras que, muitas vezes, não correspondem à realidade, mas que intranqüilizam o paciente e sua família".

\section{Grupo de pacientes \\ (Para você: o que significa "câncer"?)}

Pelas respostas encontradas nesse grupo, parece não haver um interesse maior em relação às explicações teóricas, o que é verificado na prática, mesmo quando os pacientes têm um nível intelectual, educacional e cultural elevado.

De fato, primeiramente, o paciente faz investigações acirradas em todas as vias. Porém, quando a evolução da doença modifica o 
"antes de eu ter a doença, pensava que o câncer era morte certa. Mas agora, acho que o câncer tem cura sim! E também não acho mais que esta doença é horrorosa e o nome não é mais assustador". prognóstico e a proximidade da finitude aumenta, ocorre, simultaneamente, a diminuição de "tantos" saberes. Nesse grupo, a associação à morte e "o experimentar na própria pele a vivência do câncer" faz o paciente encontrar, nessa encruzilhada da vida, explicações fora do controle biológico e científico, isto é, busca um saber nas crenças e no psicológico.

A seguir, relatam-se algumas respostas a título de ilustração:

"Deve ser uma doença que morde assim, é o tipo de um bicho que fica mordendo, pois antes de eu fazer a cirurgia ficava mordendo"; "O câncer e a Aids são iguais, são doenças brabas do mesmo jeito. A doença fica mais difícil quando a cabeça não ajuda."; "Apesar de ter contraído esta doença, é quase fatal e é muito enganosa".

Também se observa que os pacientes desistem de querer saber os detalhes da doença, mas insistem em pedir a Deus que Ihes ilumine o caminho e Ihes dê a esperança de assistirem ao amanhecer de um novo dia. Para exemplificar, eis alguns comentários: "antes de eu ter a doença, pensava que o câncer era morte certa. Mas agora, acho que o câncer tem cura sim! E também não acho mais que esta doença é horrorosa e o nome não é mais assustador".

Devido à constante associação do câncer à morte, ao receber o diagnóstico e ao submeter-se ao tratamento proposto, inicia-se também o processo do luto antecipatório da própria vida e de tudo o que terá que deixar para trás, ou seja, amigos, família, bens adquiridos e tudo o mais. Quem fica, separa-se da pessoa querida, mas permanece no contexto já construído.

Ao serem indagados sobre o significado da doença neoplásica, Leigh \& Clark, in Berger (1998), verificaram que os pacientes inclúam descrições semelhantes à morte, terminalidade, tristeza, ao medo, às quimioterapias, mutilações e à perda financeira.

Lindemann (1944) é o criador da expressão luto antecipatório, fazendo referência "à ausência de manifestação aberta de luto na época da morte, em pessoas enlutadas que já passaram pelas fases do luto normal e que se libertaram de seus elos emocionais com a pessoa falecida" Worden (1998, p. 128). Esse conceito foi adaptado ao luto que antecede a morte biológica.

Nesse morrer, o paciente experimenta a dor de se sentir enterrado antes mesmo de ter morrido. $\mathrm{O}$ suposto atestado de óbito. O processo de perda já

ocorre no momento do diagnóstico, pela associação direta à idéia da morte, lembrando que, aqui, idéia significa ver e enxergar além do visível.

Sendo assim, o que se enxerga além do dito enfraquece o registro da possibilidade de cura (dependendo do caso) e reforça a proximidade da morte. Além disso, a percepção interna - a imagem que se constrói a partir desse olhar, na maioria das ocorrências - é gradativamente confirmada pelas modificações prognósticas, no decorrer de tratamentos refratários e/ou recaídas (Carvalho, 1998).

Para o profissional da área de saúde e familiares, ao ver o paciente decair, a realidade de remissões seguidas de recaídas produz uma sensação empírica ou uma certeza simbólica de que a inevitabilidade da morte está tão próxima que desperta o apego pela vida e a consciência da morte pessoal.

A Organização Mundial de Saúde (OMS) tem uma proposta de atendimento aos familiares que deve ocorrer durante os cuidados paliativos com os pacientes e após a morte destes, ou seja, os familiares são categorizados também como pacientes, necessitam de atenção, de cuidado e atendimento terapêutico de uma equipe especializada.

\section{Grupo de Familiares (Para Você: o que Significa "Câncer"?)}

O grupo de familiares apresentou justificativas e explicações, para o aparecimento do câncer, com vivência emocional e afetiva de qualidade indesejável. Para exemplificar, reproduzem-se alguns comentários:

"É um grito da vida. Acho que a doença é fabricada, pois é a pessoa quem cria. É um grito da alma pedindo vida ou é um decreto da alma dizendo que se você não soube viver então vamos acabar com a vida."; "É uma doença difícil de ser curada que traz sofrimento e pode ser a manifestação de alguma coisa que não estava bem."; "É uma doença que a gente provoca e que aparece porque não cuidou direito. Porque a gente tem o câncer dentro da gente, então tem que cuidar. $\mathrm{O}$ meu marido está com câncer, foi descuido nosso, porque já estou vacinada, pois meu pai e tios já tiveram. Mas, o câncer deles era aquele que rasteia."; "É o resultado dos desequilíbrios funcionais do indivíduo, onde qualquer parte (finanças, família, saúde) pode se manifestar. No desequilíbrio total, pode se propagar, ou seja, proPACAR."

Por mais que a condição funcional da família seja eficaz, é perceptível que ocorre algum prejuízo, 
maior ou menor, mas acontece. Porém, apenas 1/ 10 dos familiares faz comentários sobre a doença, o estigma, a associação com a Aids e os efeitos negativos nos relacionamentos, na vida social.

De acordo com Dunlop e Hockley (1990), apud CARVALHO (1998), existem três classificações para demarcar as necessidades familiares, quais sejam: a) fadiga; b) necessidades psicológicas e c) necessidades sociais.

Por sua vez, Worden (1998) considera que, quando se vê a deterioração progressiva do paciente e se está impotente diante desse processo ininterrupto, ocorre uma identificação com o morrer, havendo uma tomada de consciência de que este também possa ser o seu fim. Tal consciência desperta sentimentos e emoções angustiantes, que podem se manifestar pela necessidade de distanciamento do que se enxerga, mas que não se quer ver. Assim, qualquer um pode recuar emocionalmente, havendo o sepultamento do doente antes da morte. A inadequação dessa reação é que pode ocorrer até mesmo no próprio doente, isto é, ele se enterra na atitude de abandono da vida e fica à espera de que a morte venha sedálo da dor da morte social.

\section{Grupo de Psicólogos (Para Você: o que Significa "Câncer"?)}

No grupo de psicólogos, houve predomínio de comentários com foco na explicação teórica. O achado é interessante, uma vez que a proposta deste estudo é explorar a representação simbólica do câncer. A pensar-se na formação acadêmica e na experiência de trabalho do grupo, poder-se-ia supor que as respostas trouxessem mais interpretações do campo simbólico.

O que se teria processado no momento da entrevista, uma vez que houve uma aparente inibição reflexiva, pois as respostas foram sucintas e, por vezes, tão genéricas que nada da especificidade do câncer foi dito? Para exemplificar, copiam-se alguns comentários: "É uma doença a ser tratada"; "É uma doença grave"; "É uma doença causada por um desenvolvimento anômalo".

O psicólogo, independentemente da teoria psicológica em que fundamenta sua prática, tem como meta propiciar o desenvolvimento do autoconhecimento para que o paciente possa construir uma boa relação consigo e com o outro. Também visa a que o paciente apreenda os enfrentamentos necessários para que a administração de acontecimentos positivos e negativos seja satisfatória.
No caso de situações de grandes impossibilidades, acompanha o paciente para que possa transformar e suplantar perdas por ele vivenciadas.

Se é assim, então, como explicar o fato de o grupo de psicólogos não ter apresentado nenhuma resposta na categoria de aprendizagem e mudança de valores? Entende-se que esse item inclua esperança e mudança na escala de valores pessoais. Se não é possível a mudança, tal fato significa que a percepção mantém o foco, isto é, os padrões repetem-se sem indícios de transformação.

O grupo de psicólogos entrevistado possui formação acadêmica e experiência hospitalar. Supõe-se, então, que haja conhecimento teórico e vivência suficiente para o profissional almejar e contribuir para a mudança perceptiva do paciente, a fim de que as perdas sejam amenizadas. No entanto, pelos comentários expressos, constata-se que a imagem internalizada não se deixa penetrar pelo fazer e o pensar, pois está mesclada pelo sentir que pode estar alicerçado na representação simbólica negativa de cada um.

As respostas superficiais mencionadas acima talvez representem uma defesa psíquica da própria imagem internalizada. Contudo, também apresentaram respostas demonstrativas do poder de influência do pensamento simbólico e das crenças perpetuadas pela fragmentação de saberes. Para exemplificar, eis alguns comentários: "É a morte sobrepujando a pulsão de vida"; "É uma desistência da vida"; "É um passaporte para a morte"; "É coisa do dito cujo".

A aflição é estabelecida conforme o foco perceptivo, e não somente em decorrência das perdas reais,

Korzybskyl, apud Balieiro (1999, p. 56), afirma que

(...) a percepção tem um caráter de representação, ou seja, de codificação, que é a transformação do objeto percebido em objetos ou elementos de outra ordem, outro código, neste caso, de caráter abstrato, mental. Estes objetos mentais não são, evidentemente, a coisa percebida, pois o subjetivo é o processo de captação do valor, uma vez que a percepção não cria o objeto mas o capta; o mesmo sucede com a valoração.

Existe um conjunto de fatores que induz o indivíduo a dar uma importância maior ou menor para o que vive. Essas regras de codificação são constituídas pelo potencial genético, personalidade e sua inserção sociocultural e histórica.

Conforme o pensamento de Werneck (1996, pp.19 e 25),
"É uma desistência da vida"; "É um passaporte para a morte"; "É coisa do dito cujo". 
(...) conhece-se o valor com a vivência da sensibilidade e não só com a idéia, num processo de racionalização (...). O esforço da razão é feito no sentido de conhecer a coisa independentemente de seu valor. Em que medida isso é possível, é difícil precisar; esse é o objetivo, o intuito, mas, ao que parece, nunca é plenamente conseguido, já que o que atrai para o conhecimento do objeto é, antes de mais nada, o seu valor.

\section{Grupo de Enfermeiros (Para Você: o que Significa "Câncer"?)}

Apesar de haver um conhecimento teórico, o nível de respostas do grupo de enfermeiros indica uma impregnação mórbida que contamina a percepção da situação como um todo. Aparentemente, o olhar está fragmentado e com um desvio focal, de modo que capta apenas as perdas, interpretadas com bases nas crenças.

Além disso, ocorrem associações que manifestam conteúdos rudimentares, pois as associações são materializadas em bichos devoradores e incontroláveis.

A seguir, serão mencionadas algumas frases que demarcam o teor simbólico: "É um bicho de sete cabeças, não tem cura, apesar de... pode ter tratamento, mas volta..."; "Tenho que câncer é como um dragão, porque ele te come com tanta voracidade que você não sabe o que fazer"; "Câncer é um bicho que te come, mas, tem vários tipos de bichos"; "Câncer é um assassino oculto, cruel e sem piedade".

\section{Grupo de Sujeitos Externos (Para você: o Que Significa "Câncer"?)}

Os sujeitos foram entrevistados, aleatoriamente, em ruas, lojas, escola e mercado. Foram abordadas dezesseis pessoas para obter os critérios de inclusão (não têm nenhuma vivência pessoal hospitalar ou familiar com diagnóstico de câncer). Seis delas eram familiares de primeiro grau de pacientes.

Apesar da inexistência do convívio com pacientes, o grupo também apresentou a morbidade - a mortalidade - como temática principal da imagem que faz quando pensa em câncer. Algumas frases são transcritas para exemplificar essa percepção: "Já penso em morte..., uma doença sem cura..., um tumor maligno. Você vê que está tratando, mas, você sabe que vai morrer do mesmo jeito"; "É uma doença que é o fim da linha, com luta, condenação e desespero"; "Nossa! É um mal incontrolável. A palavra em si é bem forte, é angustiante!".
Até mesmo reações mais agressivas surgem a partir da menção da palavra câncer. Talvez seja um demonstrativo do impacto ocorrido devido à mobilização da emoção, como neste comentário: "É uma grande filha da puta! É uma doença terrível! A natureza é interessante, ela cria mecanismos para adequar os excessos, por isto o câncer é parecido com a Aids".

O grupo também fez associações que expressam o quão grande, dominador e agressivo é o câncer. Exemplificando: "É um monstro que quando se mexe se espalha".

As informações obtidas com a primeira pergunta mostram que, independentemente da informação cultural, acadêmica e da contextualização de cada um e da história de vida, isto é, como cuidador ou cuidado, todos apresentaram respostas associadas a imagens da morte, da dor do morrer e crenças com analogias potencialmente mórbidas e com alto índice de agressividade, ou seja, imagens que sugerem haver algo ameaçador. Seja qual for a explicação, é dado a esse algo um poder de destrutividade fatal para a vida, quer seja no âmbito do corpo, quer seja no da palavra.

Retomando, as palavras mencionadas acima cuidador ou cuidado - constituem vocábulos representativos de uma posição funcional. A primeira mensagem é: preciso ter CUIDADO! A segunda mensagem subentendida é que, se você estiver sem condições de ser cuidador, então será cuidado. Nessa condição, permanecerá atado aos cuidados que o seu tratamento requer. Mas, e se for o cuidador? Também merece atenção e cuidado, uma vez que a dor pode estar enxertada naquele que cuida, isto é, no cuidaDOR.

O exercício com as palavras tem o intuito de oferecer um lembrete sério das bases mitológicas que serviram de base para Hipócrates, o sábio pai da Medicina. A referência, aqui, é relativa ao mito do médico-ferido, pois o médico também é possuidor de uma ferida. Assim como o paciente, também possui uma consciência do que é benéfico ou maléfico para o seu organismo. Se essa dualidade não for integrada internamente, corre-se o risco de haver um desequilíbrio, e o organismo pode ir em busca da homeostase, por vezes, pagando um alto preço.

Apesar da riqueza simbólica desse mito, no momento, o objetivo não é adentrar nas interpretações, mas lembrar que somos portadores da vida e da morte e, se portamos dores, importamo-nos e reagimos conforme a peculiaridade de cada um. 
Kübler-Ross (1996) considera existirem padrões de comportamentos que as pessoas, em geral, apresentam nas situações de perda, independentemente de o prejuízo envolver o campo afetivo, familiar, econômico ou da saúde.

\section{Como Você Reagiria, se Tivesse Câncer?}

Na segunda pergunta deste estudo - "Como você reagiria, se tivesse câncer?" - coloca-se uma situação hipotética, para observar as associações e confabulações, que podem ser representativas de uma projeção da subjetividade, ou seja, uma expressão do que seja "sentido mentalmente".

No caso do paciente, a pergunta - Como você reagiu, ao saber que tinha câncer? - faz parte da sua experiência real; assim, a resposta estará diretamente ligada à sua reação inicial.

Os comentários apresentados foram sistematizados conforme a proposta da psiquiatra Kübler-Ross (1996), que relaciona cinco estágios reacionais comuns em pessoas que vivenciam alguma perda. Os estágios são os seguintes: a) negação e isolamento; b) raiva; c) barganha; d) depressão; e) aceitação. Ela não se limita aos aspectos da doença, morte; sua classificação refere-se ao comportamento humano. No estudo em questão, constatou-se que as respostas são expressões dessas fases. Alguns supõem que apresentarão uma única reação, como no relato seguinte, na fase da barganha: "Faria tudo, quimioterapia, radioterapia, cirurgia, tudo, tudo...".

Em outras respostas, foi possível verificar mudanças de fase no mesmo indivíduo. Para exemplificar, eis aqui uma resposta: "Primeiro: entraria em depressão, depois procuraria ignorar". Outro exemplo: "(...) aí passaria por todas aquelas fases: negação, desespero, pânico..."

Nem todos os pacientes passam por todos os estágios ou alcançam o último, isto é, a aceitação. Além disso, a presença de um estágio não impede a presença de outro, pois podem coexistir numa justaposição, como, por exemplo, apresentar uma reação depressiva e uma negação parcial, numa situação de um pesar preparatório.

Os comentários obtidos em cada um dos grupos deste estudo estiveram predominantemente no estágio da depressão. Outro estágio que teve uma concentração de respostas foi o estágio de negação. Ao estágio da raiva, apenas um paciente expressou reação. No estágio da barganha, três pessoas (médico, psicólogo e um familiar) manifestaram o movimento de tentar tudo da Medicina, de tratamentos alternativos ao investimento religioso. Em relação ao estágio da aceitação, nenhuma pessoa do grupo de psicólogos demonstrou essa possibilidade, e a maioria apresentou, hipoteticamente, uma reação coerente com o quarto estágio, isto é, a depressão.

Vale lembrar que, na primeira pergunta, foi constatada uma superficialidade nas respostas do grupo dos psicólogos. Será que não há disposição de pensar, na medida em que os pensamentos trazem sentimentos de dor?

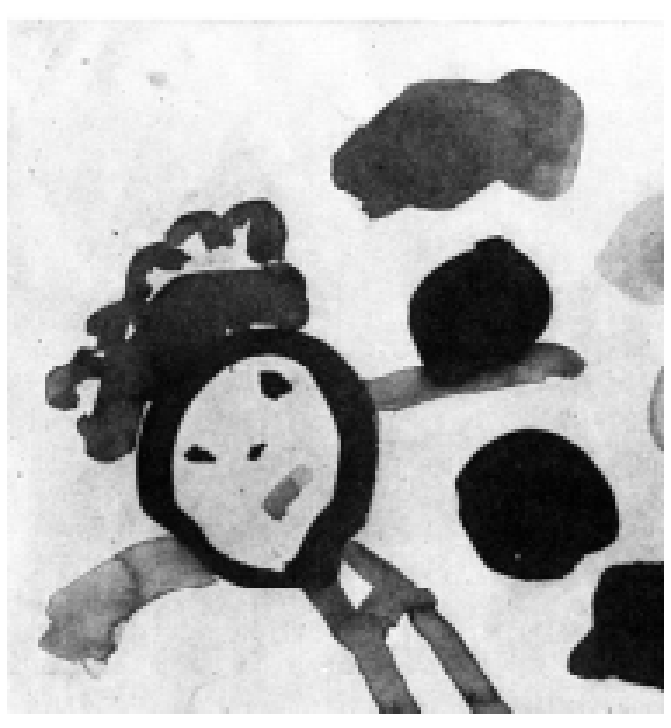

\section{Você Faz (ou Fazia) Algum Tipo de Prevenção?}

Em relação à pergunta: "Você faz (ou fazia) algum tipo de prevenção?", foi possível verificar que, no grupo de psicólogos, 7/10 fazem prevenção; no grupo de pacientes, 4/10 faziam exames periódicos; no grupo de médicos e da enfermagem, 3/10 têm este cuidado; no grupo externo ao hospital, apenas 1/10 o faz, e, no grupo familiar, nenhum faz qualquer tipo de prevenção.

Fica explícito, nesses dados, haver falta de consciência quanto ao caráter saudável da prevenção, uma vez que existem riscos de mudança de prognóstico clínico caso o câncer não seja descoberto em tempo hábil. No entanto, não ocorre o enfrentamento dessa possibilidade, quer seja com os grupos do convívio hospitalar, quer seja o próprio familiar, que, muitas vezes, perdeu outros familiares, além de estar passando pelo processo atual.
"Já penso em morte..., uma doença sem cura..., um tumor maligno. Você vê que está tratando, mas, você sabe que vai morrer do mesmo jeito"; "É uma doença que é o fim da linha, com luta, condenação e desespero"; "Nossa! É um mal incontrolóvel. A palovra em si é bemforte, é angustiante!". 


\section{Cuidar dos Pacientes com Câncer Interfere de que Forma, na Sua Vida?}

No caso da pergunta: "Cuidar dos pacientes com câncer interfere de que forma, na vida de quem cuida?, os grupos apresentaram comentários, conforme a expressão temática, classificados em: a) desvitalização emocional - depressão, amargura, tristeza, vive em função da vida do outro, estresse e sobrecarga -; b) sentimento de impotência - ameaça de perda iminente, identificação -; c) finitude consciência da própria terminalidade -; d) humanização - crescimento espiritual, apego a Deus, mudança de valores, lição de vida, aprendizagem -; e) ciência - pesquisa, responsabilidade profissional, teoria -; f) frieza afetiva - duro, calculista -; g) vocação; h) nenhuma interferência; i) não sabe.

\section{"Gostaria de não ter contato com estas pessoas.", "Quem cuida fica escravo destes pacientes e acaba deixando de viver a própria vida para viver a vida dos enfermos."; "Deve ser difícil olhar para uma pessoa que está se acabando, que está indo."; "Não interfere porque não pega.".}

Nos grupos de pacientes, de familiares e de sujeitos externos, houve uma concentração no item desvitalização emocional. A sobrecarga consome a vida do cuidador, enquanto o paciente some no seu definhar contínuo. Pode-se supor que o paciente e o familiar não possuam muitas opções quanto ao fato de a doença estar no próprio lar; então, é compreensível que as respostas falem dessa dificuldade, que avassala a estrutura emocional de todos aqueles diretamente envolvidos com a enfermidade. Eis alguns comentários mencionados pelos pacientes:

"Tornou-se uma pessoa nervosa, ficou esquecida, não lembra mais das coisas e chora a toda hora. O médico falou que o tratamento é só para prolongar a vida. Então por que vou fazer tratamento se não vou usar a vida?!"; "Qualquer tipo de doença é preocupante para a pessoa, mas o câncer está na gravidade alta, é um sofrimento muito grande."; "Eles tem que deixar a vida deles toda para trás, a gente toma tudo deles".

Também existem respostas contraditórias, com negações parciais em relação aos sentimentos e à emoção que essa vivência causa; por exemplo: a paciente responde que não existe interferência alguma, mas, no significado do câncer, havia dito que: "câncer é um trauma grande porque é uma doença incurável". Em relação aos comentários de familiares: "O doente, o é por uma semana, depois passa a ser um estorvo". Vê o paciente como se fosse um parasita que suga a seiva de uma árvore enraizada no compromisso de cuidar até o fim e que, por vezes, o término se arrasta como erva daninha. Outros comentários podem ser conferidos: "É difícil, porque dia a dia vai indo."; "Parece que parei de viver, mudou tudo. Vejo ele sofrendo, sofro junto. Quando ele está bem, tô bem, se está mal, tô mal".
No grupo de sujeitos externos, ou seja, isento do convívio com doentes, ao comentarem sobre o que imaginam que deva acontecer com familiares ou com os profissionais da área de saúde, expressam idéias de sobrecarga de vida, o que gera um abandono de projetos, sonhos e até mesmo da própria vida, como pode ser observado em alguns comentários: "Gostaria de não ter contato com estas pessoas."; "Quem cuida fica escravo destes pacientes e acaba deixando de viver a própria vida para viver a vida dos enfermos."; "Deve ser difícil olhar para uma pessoa que está se acabando, que está indo."; "Não interfere porque não pega.".

Em relação ao grupo de médicos, este último manifestou identificação com o processo de muitas lutas e desistências necessárias nesse ir-e-vir dos pacientes. Alguns reagem com o esfriamento, outros se envolvem com os paciENTES; assim, também apresentam sentimentos de impotência e medo de serem os próximos por ficarem tão perto da consciência da finitude e da dor desse convívio.

Também foram fornecidas respostas de valorização à vida e mudanças de valores, devido à necessidade de trazer humanização a um contexto que requer cuidados que vão além do conhecimento científico.

O médico possui, desde os primórdios, o peso de uma imagem de saber, poder e da capacidade de tomar decisões fundamentais para o direcionamento do tratamento do paciente. Desse modo, há uma responsabilidade enorme com a atualização e as pesquisas que contribuam para o conhecimento científico. Apesar de ser uma área extensamente explorada, verifica-se que os comentários dos médicos mostram uma interferência significativa dos aspectos que fazem um chamamento para a humanização, a valorização e a busca de uma filosofia de vida que dignifique o seu fazer.

O sofrimento do paciente, por vezes, desperta o médico para a consciência do próprio sofrimento que aí está ou que está por vir. Alguns comentários: "Passa a enxergar seus problemas de forma mais amena. Mas, também tem que tomar cuidado porque a tendência é criar uma barreira para não sofrer tanto e pode se tornar frio. A morte deixa de ser tão grave. Para mim, a morte não é um fim, o espírito continua".

No grupo de enfermeiros, verifica-se acentuada interferência nos comportamentos devido à labilidade emocional, sentimentos de impotência, identificação com o doente e transposição do que presencia para a possibilidade de acontecer consigo ou com os seus. Contudo, também houve comentário com teor defensivo, como, por 
exemplo; "Não me apego muito, fico abalada só no momento. Morre, enterra! Sou totalmente fria em relação a tudo. Consigo fazer um corte drástico. Fico me perguntando se isto é normal?!". Pode-se afirmar que tal interpretação demonstra um desejo de proteção em relação ao que vê, mas que não quer - ou não pode - enxergar.

De todos os grupos, apenas neste houve a menção de que sofrimentos e perdas fazem parte de um trabalho de vocação e de realização profissional, já que tais enfermeiros consideram seu trabalho uma oportunidade de ajudar o próximo e fazer o bem dentro do que seja possível. Algumas respostas para ilustração: "É positivo poder dar assistência integral ao paciente"; "É uma satisfação trabalhar com eles, é uma maneira de ajudar o próximo, é um prazer lidar com eles".

Tal disponibilidade talvez possa ser entendida pela base histórica da formação dessa profissão, especificamente constituída num contexto sem qualificação; sim, pois os primórdios da profissão de enfermagem apontam as meretrizes como as primeiras mulheres a desempenharem essa função. Elas eram convocadas para cuidar de pacientes marginalizados, de nível socioeconômico baixíssimo e com doenças como a lepra. Assim, as primeiras pessoas a assumir esse papel, fundamental para a vida dos pacientes, tiveram a possibilidade de ocupar outra posição perante a sociedade e perante si mesmas.

Desse modo, é possível inferir que esse fazer esteja de algum modo associado à imagem internalizada, isto é, a uma atitude de reparação de uma ação indesejável. Assim, o desejo ganha força na realização de doação e cuidado, apesar da dor. Conforme tal raciocínio, é compreensível a satisfação derivada da assistência.

Segundo Nunes Silva (2000), antes de 1900, havia uma escuta da história pessoal do paciente porque não se sabia o que fazer em relação ao aparecimento do câncer; então, fazia-se o atendimento sem saber como deveria ser feito, ou seja, ouvir o doente falar de si por meio de sua doença representava um horizonte de possibilidade de compreensão acerca da enfermidade, e, por efeito, de encontro da respectiva cura.

No início do século XX, houve uma corrida desenfreada em busca de novas drogas e tratamentos que se mostrassem mais eficientes e promissores.
Atualmente, temos uma tecnologia avançada, com a ciência desenvolvendo hipóteses que dão viabilidade a novos experimentos. Então, deparamo-nos com o prolongamento da vida, mas, em razão de dificuldades que, muitas vezes, extrapolam a estrutura subjetiva de cada um, em decorrência de crises que perpassam o aspecto socioeconômico, e mesmo cultural, da população, constata-se haver a tendência de encurtamento das condições de cidadania para uma vida digna e qualitativa.

\section{Questões Acerca da Qualidade de Vida}

Para verificar como o conceito de qualidade de vida tem sido considerado, os grupos avaliados responderam às seguintes perguntas: "Para você: o que é qualidade de vida?" e "Numa escala de zero a dez, quanto de qualidade de vida você tem hoje?" Pergunta para o cuidador: "Se você tivesse algum tipo de câncer que necessitasse de pelo menos dois desses tratamentos: quimioterapia, radioterapia, transplante de medula óssea e/ou cirurgia, como ficaria a sua qualidade de vida?"

Foi feita a seguinte pergunta ao paciente: "Quanto você tinha de qualidade de vida antes dos primeiros sinais do câncer?"

Observou-se, nas respostas encontradas, que a grande maioria concorda com a ocorrência de uma redução significativa na qualidade de vida, quer seja na avaliação da realidade vivenciada pelo paciente ou familiar, quer seja nos casos em que a análise corresponde ao imaginário do profissional de saúde e daquele que não tem uma relação direta com a realidade oncológica.

Ao elaborarem o conceito de qualidade de vida, incluem elementos com características positivas, multidimensionais e que dependem do jeito de interpretar, isto é, um mesmo fenômeno pode ser bom ou ruim conforme a peculiaridade de quem olhe. Os elementos mencionados foram: saúde, prazer, condições econômicas favoráveis, trabalho, família, amigos, espiritualidade e condições emocionais de bem-estar.

Em todos os grupos, o item da saúde e da possibilidade de fazer o que gosta e com prazer foram os mais mencionados. Eis um expressivo comentário de um paciente: "Sabe que esta é uma pergunta muito complicada? Perguntei outro dia para um pastor: O que é ser feliz? Envolve muitas coisas, como a qualidade de vida". 


\section{Que Cor você Associa ao Câncer?}

Em relação à perguntas: "Que cor você associa ao câncer? Por quê?", as respostas mencionadas foram:

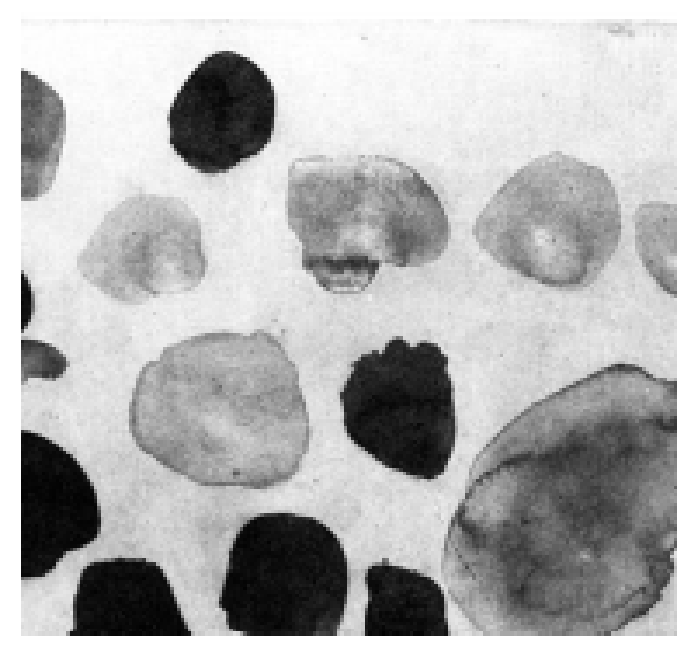

PRETO: "Porque lembra luto, morte, dor, tristeza, perda, gelo, aquilo que é feio e que não tem vida. Preto fosco porque a cor opaca chupa."; "Veio a cor preta. Acho que não é por mim, porque é a cor que mais gosto. Acho que é mais pelo que as pessoas pensam e falam."; CINZA: "Porque a pele dos pacientes fica com cor de asfalto, sem vida. Porque lembra túmulo, dor, tristeza, pura morte, desesperança, sofrimento, sombra. Lembra um dia de tempo ruim, nublado. É escuro, é sombra, então é cinza. Também lembra fungos. As pessoas ficam com jeito de queimada. Porque é uma situação indefinida, não é nem sol nem chuva. Tanto pode trazer a paz como a dor."; "O preto é morte, o branco é luz, então escolho cinza porque significa que a pessoa está desistindo da vida."; BEGE ACINZENTADO, ESVERDEADO, AMARELADO: "Porque dá a idéia de podridão e decomposição."; BRANCO: "Porque é de impasse, é indefinido. Branco, preto não pode ser de jeito nenhum!"; "Quando o meu avô estava com câncer, ele ficava no quarto dele que era todo branco e muito limpo. Então o branco lembra este lugar que meu avô ficou para morrer."; MARROM: "Porque mata, mas mata aos poucos. Lembra que é um retorno para a terra, morre e isto é feio e sujo. Escolho marrom, mas não sei por quê, talvez seja cor de merda, meu irmão morreu de câncer de intestino."; "Também lembra fungos. As pessoas ficam com jeito de queimada. Porque é uma situação indefinida."; ROXO: "Porque lembra morte, perda, dor, tristeza. É como um leito que não tem como retornar."; "Porque lembra o raio x."; AZUL: "Por causa da roupa do hospital."; VERMELHO: "Por causa da relação com sangue, pela ligação com os órgãos internos. Lembra cirurgia, hospital, quimioterapia."; "Porque é forte e causa impacto, como o câncer."; AMARELO: "Lembra cor de doente, febre e palidez."; "Quando tiraram um pedaço do meu abdômen, falaram que parecia um músculo amarelado."; "Porque é uma cor bem nojenta, um amarelo esverdeado com alguns pontos brancos e cinza de fungos. Porque é isto que me veio de imediato."; VERDE: "Porque os pacientes, com o tempo, vão ficando verdes."; "Verde de esperança tem que ter um pouco.".

Ao darem as justificativas - menos em relação à cor verde - todos os grupos dão uma conotação negativa e de perda. A seguir, pode-se verificar o comentário de um profissional da área de saúde: "Preto porque representa luto e o câncer sempre é associado à morte. Acho que ainda estou condicionado com a imagem não profissional".

A cor invoca a emoção contida na contextualização e esta se mostra carregada de sentido relacionado a impressões desagradáveis. Por vezes, há tentativas inconscientes de não incluir a cor que espontaneamente surge. Com um movimento de reparação, nega a cor selecionada pela emoção e inclui a cor que a razão lhe diz ser a indicada. Por exemplo: "Preto não! Preto é luto, não pode! Tem que ser verde esperança, verde de que a gente vai chegar lá". Outro exemplo: "Escolho azul, porque azul é tranqüilo, porque tem cura. Enquanto que vermelho não pode ser porque é coisa ruim".

De modo geral, os entrevistados demonstraram estranheza diante da pergunta, mas mencionar a cor fazia com que entrassem em contato com o sentir, no primeiro instante, e não com o pensar. Um comentário imediato foi o seguinte: "Colorido é que não é!"

De acordo com Spink (1999), a representação pessoal é subjetiva, porém também deriva de aspectos partilhados de uma representação social. Se o imaginário social tem uma repercussão no comportamento, então deve-se refazer a imagem para que haja uma mudança real da atitude. É preciso tomar cuidado para não se deixar levar simplesmente pela representação simbólica, de modo a não se enxergarem os sinais das situações em que se está inserido.

Na medida em que pode promover interlocução e nominação do que é próprio da linguagem subjetiva, numa relação interpessoal, a comunicação social compreende a experiência individual e os valores sociais. Assim, pode-se dizer que, ao falar-se do binômio saúde-doença, fica subentendida a presença de elementos relacionados ao ambiente físico e social. Segundo Moscovici (2004), um conjunto de palavras viabiliza 
a construção das imagens do objeto em questão; em conseqüência, o indivíduo faz associações a um significado concreto. Tal conjunto é formado por uma combinação incorporada pelo núcleo figurativo, ou seja, pela imagem estrutural que reproduz o conteúdo conceitual.

Para amenizar a angústia, a tendência é buscar uma interpretação, um sentido para aquilo que incomoda, sentido que pode compensar ou pesar na construção perceptiva. Assim, a representação simbólica negativa é uma fonte de angústia que, por si, destrói as possibilidades de aproveitamento dessa vivência.

Investigar o simbolismo e falar sobre o impacto e o registro imagético do câncer propiciará ao indivíduo um espaço para entrar em sintonia com suas necessidades recíprocas (interna e externa). Com isso, talvez seja possível a aceitação da condição real e, assim, de um manejo mais adequado em relação ao seu estado de saúde. Todavia, a presença do conceito não deve satisfazer. É preciso que se busque o conhecimento do que constitui essa presença.

Para Remen (1992), a saúde humana recebe interferências da realidade objetiva e da subjetiva. No âmbito da subjetividade, existe um mundo singular, composto por sentimentos, pensamentos e atitudes, que pode limitar a evolução do tratamento. Ao mesmo tempo, a depender de como se processe, pode contribuir positivamente para minimizar o mal-estar do paciente e de seus interlocutores.

Por sua vez, Torres (1983) argumenta que a patologia social contemporânea decorre significativamente da negação da morte na expectativa de vida diária.

Conforme Kübler-Ross (1996), no entanto, é fundamental compartilhar os sentimentos para não adoecer e morrer. O medo maior está na relação com o morrer, pois engloba sentir dor e passar pelo processo de separação. Quando é possível falar sobre a desesperança, o desamparo, o isolamento, observa-se que o nível de angústia e ansiedade se reduz, podendo-se olhar sob uma nova perspectiva para a própria morte.

\section{Conclusão}

\section{Pensar, sentir, fazer: caminhos de saúde ou enfermidade}

Se ignoramos nossas necessidades básicas, tornamonos partícipes da estruturação do adoecimento por meio da atividade mental, física e emocional. A sobrecarga de tensões, emoções e desagrados sobre o indivíduo pode despertar-lhe a atenção somente quando o corpo tornar-se sinalizaDOR da manifestação patológica.

Uma das soluções para amenizar a interferência negativa decorrente das interferências da coletividade é apreender quais pensamentos, atitudes e emoções propiciam comportamentos doentios e/ou saudáveis, pois a análise dos processos mentais abre a perspectiva da conscientização de que somos um corpo que possui uma identidade simbólica e, como tal, portaDOR de histórias que vão muito além dos registros dos sistemas orgânicos do DNA.

Este estudo objetivou uma reflexão para que se constitua uma redefinição da própria atitude em relação ao câncer, doença potencialmente mórbida, que nos consome pela aparição da finitude que define a proximidade do fim de cada um.

A dor do morrer traz a consciência de que o profissional nem sempre pode evitar a concretização do temor maior, ou seja, a confirmação da morte, nem mesmo a que ilusoriamente lhe pertence.

Então, é fundamental que o paciente e a família sejam beneficiados pela rede social de apoio, que recebam suporte no transcorrer do tratamento. Portanto, vale pensar sobre a imagem simbólica que o staff da oncologia/hematologia internalizou, uma vez que a imagética influencia na percepção, na reação e na distribuição do tempo que cada um determinará para a escuta da singularidade daquele que adoeceu com o câncer e/ou com a contaminação simbólica.

Um estudo dessa natureza pode contribuir para que se busquem formas de aprimorar o tratamento do paciente com câncer. No entanto, para ajudar o outro, é preciso, primeiramente, redimensionar a própria formação imagética; afinal, nós também somos semeadores das imagens que se reproduzem ao longo dos séculos, apesar de toda a evolução científica.

É preciso preparar-se para a morte, pois essa conscientização apura e melhora a qualidade de vida. Além disso, o confronto com a finitude afeta o homem individual e também socialmente.

É de grande valia, como atitude salutar, que nós, profissionais da área de saúde, estejamos cientes de que também temos necessidades provenientes da nossa construção simbólica.

Necessitamos da perspicácia e da sensibilidade para apreender o conhecimento humano da finitude e, para tal, é preciso olhar de frente para o que nos cega e, por isso, nos seca.

Afinal, o que sabemos do amanhã?! 
Número: Local da entrevista:

Data: Nome ou iniciais:

( ) Paciente ( ) Familiar ( ) Profissional de saúde ( ) Externo

( ) Masculino ( ) Feminino

Idade: Data de nascimento:

Estado Civil: ( ) solteiro ( ) casado ( ) separado ( ) divorciado ( ) viúvo

Dependentes:

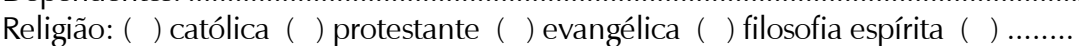

Escolaridade máxima:

Profissão:

Se paciente e/ou familiar: Diagnóstico:

Tratamentos feitos:

1 Para você: o que significa "câncer"?

2 Pergunta para o cuidador: Como você reagiria se tivesse câncer?

Pergunta para o paciente: Como você reagiu ao saber que tinha câncer?

3 Você faz (ou fazia) algum tipo de prevenção?

4 Cuidar dos pacientes com câncer interfere de que forma, na vida de quem cuida?

5 Para você: o que é qualidade de vida?

6 Numa escala de zero a dez, quanto de qualidade de vida você tem hoje?

7 Pergunta para o cuidador: Se você tivesse algum tipo de câncer que necessitasse de pelo menos dois desses tratamentos: quimioterapia, radioterapia, transplante de medula óssea e/ou cirurgia, como ficaria a sua qualidade de vida?

Pergunta para o paciente: Quanto você tinha de qualidade de vida antes dos primeiros sinais do câncer?

8 Que cor você associa ao câncer? Por quê?

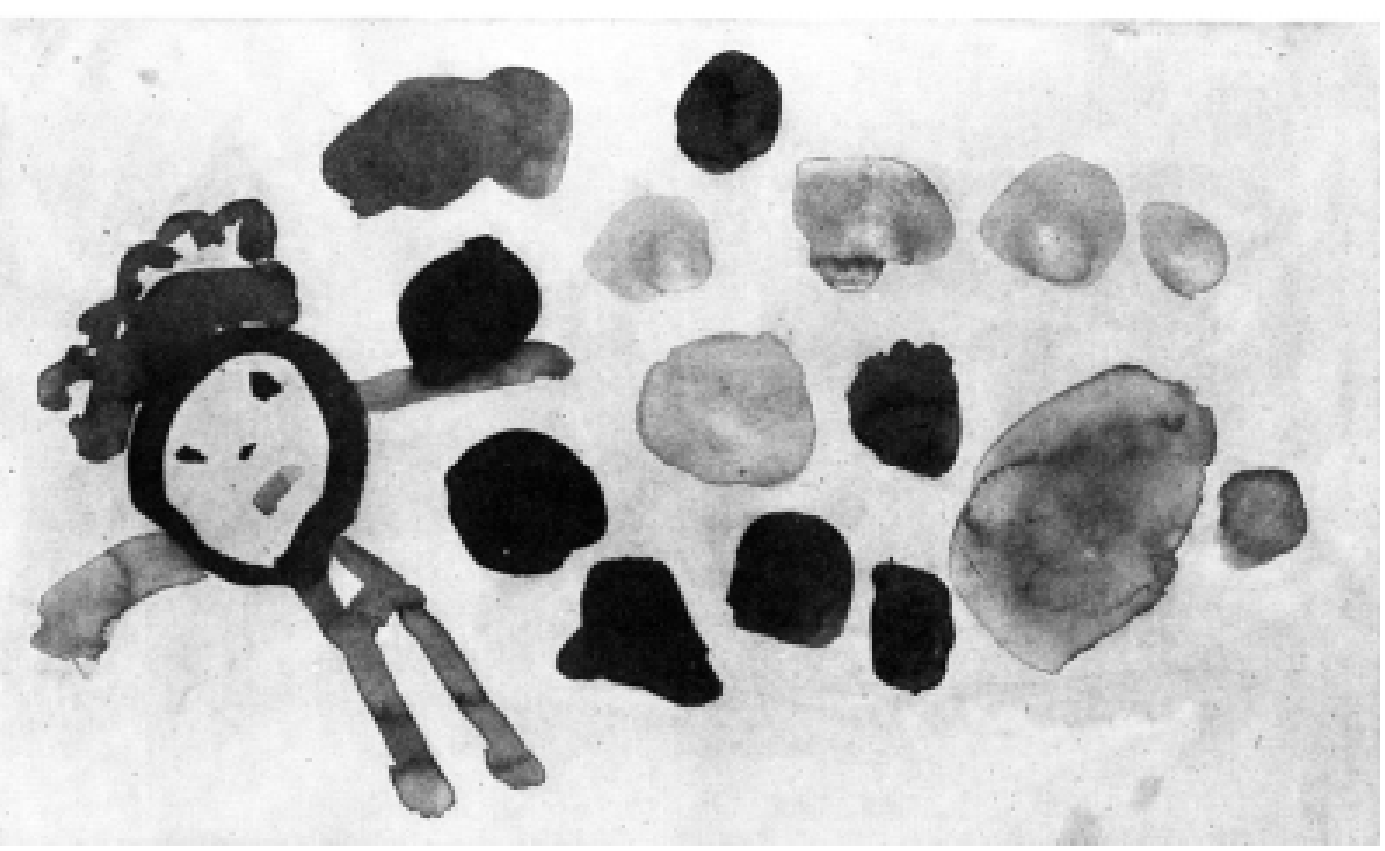


Maribel Pelaez Dóro, Ricardo Pasquini, Carlos R. Medeiros, Marco Antonio Bitencourt \& Glaci L. Moura R. Adolfo Stedile, $201-$ Bom Retiro 80520-540 - Curitiba - PR (41) 254-7107 223-5078/99610450 E-mail:maripdoro@uol.com.br

BALIEIRO, A P. Junior. Mecanismos do Poder Corruptor. Psicologia ciência e profissão, 1999 (3): pp.52-9.

CARVALHO, M. M. M. J. Resgatando o Viver. São Paulo: Summus, 1998. GUERRIERO, S.; RIBAS, J.B.C.; KEMP, K.; PASSADOR, L.H. \& FERRARI, M. D. Antropos e Psique. 2. ed. São Paulo : Olho d'Água, 2001.

KARPINSKI, G. D. As Sete Etapas de uma Transformação Consciente. São Paulo: Pensamento, 1990

KÜBLER-ROSS, E. Sobre a Morte e o Morrer. 7. ed. São Paulo: Martins Fontes, 1996.

LESHAN, L. O Câncer Como Ponto de Mutação. São Paulo: Summus, 1992.

MOSCOVICI, S. Representações Sociais. Investigações em Psicologia Social. 2 edição. Petrópolis RJ. Editora Vozes, 2004
NUNES SIIVA, C. Como o Câncer (Des)estrutura a Família. São Paulo: Annablume, 2000

SCHULZE, N. O Núcleo Figurativo das Representações de Saúde e Doença. Temas em Psicologia. n. 2, 1994.

SIMONTON, O. C.; SIMONTON, S. M. \& CREIGHTON, J. L. COM a Vida de Novo. São Paulo: Summus, 1978.

TORRES, W. C. ; GUEDES, W. G. \& TORRES, R. C. A Psicologia e a Morte. Rio de Janeiro: Fundação Getúlio Vargas, 1983.

WERNECK, V. Educação e Sensibilidade - um Estudo Sobre a Teoria dos Valores. Rio de Janeiro: Forense Universitária, 1996.

WORDEN, J. W. Terapia do Luto. Um Manual Para o Profissional de Saúde Mental. 2. ed. Porto Alegre: Artes Médicas, 1998. 